\title{
Neoleptosphaeria jonesii sp. nov., a novel saprobic sexual species, in Leptosphaeriaceae
}

\section{Wanasinghe $\mathrm{DN}^{1,2}$, Camporesi $\mathrm{E}^{3,4}$ and Hu $\mathrm{DM}^{1}$}

${ }^{1}$ College of Bioscience and Bioengineering, Jiangxi Agricultural University, Nanchang 330045, China

${ }^{2}$ Center of Excellence in Fungal Research, Mae Fah Luang University, Chiang Rai, 57100, Thailand

${ }^{3}$ Società per gli Studi Naturalistici della Romagna, C.P. 144, Bagnacavallo (RA), Italy

${ }^{4}$ A.M.B. Gruppo Micologico Forlivese "Antonio Cicognani”, Via Roma 18, Forli, Italy; A.M.B. Circolo Micologico “Giovanni Carini”, C.P. 314, Brescia, Italy

Wanasinghe DN, Camporesi E, Hu DM 2016 - Neoleptosphaeria jonesii sp. nov., a novel saprobic sexual species, in Leptosphaeriaceae. Mycosphere 7 (9), 1368-1377, Doi 10.5943/mycosphere/7/9/10

\begin{abstract}
Neoleptosphaeria is a genus of ascomycetes known only from its asexual morphs (coelomycetous) and its species have saprobic and / or endophytic life modes. We obtained LSU, SSU and ITS sequence data from a single spore isolation of a freshly collected specimen. A phylogeny of representative strains of the genus and other taxa in Leptosphaeriaceae was obtained. Neoleptosphaeria proved to be strongly monophyletic but related to other genera in Leptosphaeriaceae. Phylogenetic analyses place our new isolate in a strongly supported clade with the generic type of Neoleptosphaeria ( $N$. rubefaciens). The sexual morph of Neoleptosphaeria is therefore established and includes the first genus with muriform ascospores in Leptosphaeriaceae.
\end{abstract}

Keywords - asexual morph - dictyospores - Italy - phylogeny - taxonomy

\section{Introduction}

Barr (1987) established the family Leptosphaeriaceae species with having a conical or globose ascomata, narrow asci with thin walls and coelomycetous asexual morphs in the order Pleosporales. Leptosphaeriaceae is typified by the genus Leptosphaeria and taxa in the family can be saprobic, hemibiotrophic or parasitic on stems and leaves of herbaceous or woody plants in terrestrial habitats (Hyde et al. 2013, Ariyawansa et al. 2015, Liu et al. 2015, Hyde et al. 2016). The classification of genera and species in Leptosphaeriaceae has been challenging due to the lack of understanding of the significance of morphological characters used to differentiate taxa, as well as the lack of DNA based molecular data from ex-type strains (Ariyawansa et al. 2015). Hyde et al. (2013) provided an inclusive view of Leptosphaeriaceae and accepted Leptosphaeria, Neophaeosphaeria, Paraleptosphaeria (sexual genera) Heterospora, Plenodomus and Subplenodomus (asexual genera) in the family. Alves et al. (2013) introduced Alternariaster to accommodate Alternaria helianthi as the first hyphomycetous record for Leptosphaeriaceae based on morphology coupled with DNA sequence data, while 
Trakunyingcharoen et al. (2014) placed Sphaerellopsis in the family. Ariyawansa et al. (2015) provided comprehensive descriptions for all genera in Leptosphaeriaceae along with illustrations and a well-resolved backbone tree. Ariyawansa et al. (2015) excluded Neophaeosphaeria from Leptosphaeriaceae and introduced Alloleptosphaeria, Neoleptosphaeria and Pseudoleptosphaeria in the family based on evidence from molecular phylogeny, as well as morphological characters. Liu et al. (2015) introduced Leptosphaeria ebuli as a new species, Paraleptosphaeria nitschkei and Plenodomus agnitus as reference specimens to Leptosphaeriaceae based on both molecular data coupled with morphology. Hyde et al. (2016) updated the phylogeny of Leptosphaeriaceae by introducing Leptosphaeria cirsii and L. irregularis as new species to Leptosphaeria.

This paper reports on a saprobic Leptosphaeriaceae species which was collected on dead twigs of Clematis vitalba in Italy and identified as a new species of Neoleptosphaeria. Combined analyses of LSU, SSU and ITS sequence data, using maximum-likelihood (ML), maximum-parsimony (MP) and Bayesian analyses (BYPP), clearly show that Neoleptosphaeria is a well-supported genus (90\% ML / 99\% MP / 1.00 BYPP, Fig. 1) in the family.

\section{Materials and methods}

\section{Sample collection, morphological studies and isolation}

Fresh material was collected from Forlì-Cesena Province in Italy and brought to the laboratory in Zip lock plastic bags. Samples were examined with a Motic SMZ 168 Series microscope. Hand sections of the fruiting structures were mounted in water for microscopic studies and photomicrography. The taxa were examined using a Nikon ECLIPSE 80i compound microscope and photographed with a Canon 550D digital camera fitted to the microscope. India ink was added to water mounts to show the presence of a gelatinous sheath around the ascospores. Measurements were made with the Tarosoft (R) Image Frame Work program and images used for figures processed with Adobe Photoshop CS3 Extended version 10.0 software (Adobe Systems, USA).

Single ascospore isolation was carried out following the method described in Chomnunti et al. (2014). Germinated spores were individually transferred to Potato dextrose agar (PDA) plates and grown at $16^{\circ} \mathrm{C}$ in the daylight. Colony colour and other characters were observed and measured after three weeks. The specimens are deposited at the Mae Fah Luang University (MFLU) Herbarium, Chiang Rai, Thailand. Living cultures are deposited at the Culture Collection of Mae Fah Luang University (MFLUCC). Faces of Fungi number is provided in Jayasiri et al. (2015) and Index Fungorum numbers as in Index Fungorum (2016).

\section{DNA extraction and PCR amplification}

Fungal isolates were grown on potato-dextrose agar (PDA) for 3-4 weeks at $16{ }^{\circ} \mathrm{C}$ and total genomic DNA was extracted from fresh mycelium using the Biospin Fungus Genomic DNA Extraction Kit-BSC14S1 (BioFlux, P.R. China) following the instructions of the manufacturer. The DNA extractions were stored at $4{ }^{\circ} \mathrm{C}$ for regular use and duplicated at $-20{ }^{\circ} \mathrm{C}$ for long term storage.

DNA amplification was performed by polymerase chain reaction (PCR). Three partial gene portions were used in this study: the internal transcribed spacers (ITS), the large subunits of the nuclear ribosomal RNA genes (LSU) and small subunits of the nuclear ribosomal RNA genes (SSU). ITS was amplified using the primers ITS5 (5'-GGAAGTAAAAGTCGTAACAAGG-3') and ITS4 (5'TCCTCCGCTTATTGATATGC-3') (White et al. 1990). LSU was amplified using the primers LROR (5'-TCCTGAGGGAAACTTCG-3') and LR5 (5'-ACCCGCTGAACTTAAGC-3') (Vilgalys \& Hester 1990, Rehner \& Samuels 1994). SSU was amplified using the primers NS1 (5'GTAGTCATATGCTTGTCTC-3') and NS4 (5'-CTTCCGTCAATTCCTTTAAG-3') (White et al. 1990). The PCR thermal cycle program for ITS, LSU and SSU amplification was as follows: initially denaturing step of $94{ }^{\circ} \mathrm{C}$ for $4 \mathrm{~min}$, followed by 35 cycles of denaturation at $94{ }^{\circ} \mathrm{C}$ for $45 \mathrm{~s}$, annealing 
at $56{ }^{\circ} \mathrm{C}$ for $45 \mathrm{~s}$, elongation at $72{ }^{\circ} \mathrm{C}$ for $1 \mathrm{~min}$, and a final extension at $72{ }^{\circ} \mathrm{C}$ for $10 \mathrm{~min}$. The amplified PCR fragments were sent to a commercial sequencing provider (BGI, Ltd Shenzhen, P.R. China). The nucleotide sequence data acquired were deposited in GenBank (Table 1). The finalized alignment and tree were deposited in TreeBASE, submission ID: 20235 (http://www.treebase.org/).

\section{Sequencing and sequence alignment}

Sequences generated from different primers were analyzed with other sequences from GenBank. The related sequences were determined using a BLAST search to recognize closest matches with taxa in Leptosphaeriaceae and recently published data (Ariyawansa et al. 2015, Liu et al. 2015, Hyde et al. 2016). Sequences were automatically aligned with MAFFT v. 7 (http://mafft.cbrc.jp/alignment/ server/index.html; Katoh \& Standley 2013), and improved manually when necessary using BioEdit v. 7.0.5.2 (Hall 1999).

\section{Phylogenetic analysis}

Phylogenetic analyses of both individual and combined aligned data consisted of maximumlikelihood, maximum parsimony and Bayesian analyses. The sequence alignments were converted to NEXUS file (.nex) for maximum parsimony and Bayesian analyses using ClustalX2 v. 1.83 (Thompson et al. 1997). The NEXUS file was prepared for MrModeltest v. 2.2 after deleting the symbols ="ABCDEFGHIKLMNOPQRSTUVWXYZ" (Nylander 2004) in PAUP (Phylogenetic Analysis Using Parsimony) v. $4.0 \mathrm{~b} 10$ (Swofford 2002). For the Randomized Accelerated Maximum Likelihood (RAxML) analysis, sequence alignments were converted to PHYLIP file (.phy) using ALTER (alignment transformation environment: http://sing.ei.uvigo.es/ALTER/; 2016). Parsimony analysis was performed in PAUP using the heuristic search option with 1000 random sequence additions and tree bisection-reconnection (TBR) via branch swapping algorithm. All molecular characters were unordered and given equal weight, analyses were performed with gaps treated as missing data; the COLLAPSE command was set to minbrlen. Maxtrees were set at 5000, branches of zero length were collapsed and all multiple, equally parsimonious trees saved. Clade constancy was measured using bootstrap (BT) analysis with 1000 replicates, with 10 replicates of each random stepwise addition of sequences. Descriptive tree statistics for parsimony; Tree Length (TL), Consistency Index (CI), Retention Index (RI), Relative Consistency Index (RC) and Homoplasy Index (HI) were calculated for trees generated under different optimality criteria. The Kishino-Hasegawa tests (Kishino \& Hasegawa 1989) were performed to determine whether trees were significantly different. Maximum parsimony bootstrap values equal or greater than $70 \%$ are given above each node (Fig. 1). The evolutionary models for Bayesian analysis and maximum-likelihood were selected independently for each locus using MrModeltest v. 2.3 (Nylander 2004) under the Akaike Information Criterion (AIC) implemented in both PAUP v. 4.0b10. The GTR+I+G model resulted in each locus for Bayesian and maximum-likelihood analyses by AIC in MrModeltest as a best-fit model.

Bayesian analysis was performed in MrBayes v. 3.1 .2 (Huelsenbeck \& Ronqvist 2001) to evaluate Posterior probabilities (PP) (Rannala \& Yang 1996, Zhaxybayeva \& Gogarten 2002) by Markov Chain Monte Carlo sampling (BMCMC). Six simultaneous Markov chains were run for $50,000,000$ generations and trees were sampled every 5000th generation. The distribution of loglikelihood scores was examined to determine stationary phase for each search and to decide if extra runs were required to achieve convergence, using the program Tracer 1.5 (Rambaut \& Drummond 2007). All sampled topologies beneath the asymptote (10\%) were discarded as part of a burn-in procedure; the remaining trees were used for calculating posterior probabilities (PP) in the majority rule consensus tree. BYPP greater than 0.95 are given above each node (Fig. 1).

Maximum likelihood trees were generated using the RAxML-HPC2 on XSEDE (8.2.8) (Stamatakis 2008, 2014) in the CIPRES Science Gateway platform (Miller et al. 2010) using GTR+I+G model of evolution. Maximum likelihood bootstrap values (ML) equal or greater than $70 \%$ 
Table 1 Taxa used in the phylogenetic analysis and their corresponding GenBank numbers. The newly generated sequence is indicated in bold.

\begin{tabular}{|c|c|c|c|c|}
\hline \multirow{2}{*}{ Taxon } & \multirow{2}{*}{ Culture accession no. } & \multicolumn{3}{|c|}{ GenBank accession no.* } \\
\hline & & ITS & LSU & SSU \\
\hline Alloleptosphaeria italica & MFLUCC 14-0934 & KT454722 & KT454714 & NA \\
\hline Alternariaster bidentis & CBS 134021 & KC609333 & КC609341 & KC609347 \\
\hline Alternariaster centaureae-diffusae & MFLUCC 14-0992 & KT454723 & KT454715 & KT454730 \\
\hline Alternariaster centaureae-diffusae & MFLUCC 15-0009 & KT454724 & KT454716 & KT454731 \\
\hline Alternariaster helianthi & CBS 327.69 & KC609335 & KC584369 & KC584627 \\
\hline Camarosporium aborescentis & MFLUCC 14-0604 & KP711377 & KP711378 & KP711379 \\
\hline Camarosporium arezzoensis & MFLUCC 14-0238 & KP120926 & KP120927 & KP120928 \\
\hline Camarosporium aureum & MFLUCC 14-0620 & NR_137970 & KP744478 & KP753948 \\
\hline Camarosporium caraganicola & MFLUCC 14-0605 & KP711380 & KP711381 & KP711382 \\
\hline Coniothyrium palmarum & CBS 400.71 & AY720708 & EU754153 & AY642513 \\
\hline Coniothyrium palmarum & CBS 758.73 & NA & JX681085 & EU754055 \\
\hline Cucurbitaria berberidis & CBS 394.84 & NA & JX681088 & GQ387544 \\
\hline Cucurbitaria berberidis & MFLUCC 11-0386 & NA & КC506796 & KC506800 \\
\hline Didymella exigua & CBS 183.55 & GU237794 & EU754155 & EU754056 \\
\hline Heterospora chenopodii & CBS 115.96 & JF740227 & EU754188 & EU754089 \\
\hline Heterospora chenopodii & CBS 448.68 & FJ427023 & EU754187 & EU754088 \\
\hline Heterospora dimorphospora & CBS 165.78 & JF740204 & JF740281 & JF740098 \\
\hline Heterospora dimorphospora & CBS 345.78 & NR_111618 & GU238069 & GU238213 \\
\hline Leptosphaeria cichorium & MFLUCC 14-1063 & KT454720 & KT454712 & KT454728 \\
\hline Leptosphaeria doliolum & MFLU 15-1875 & KT454727 & KT454719 & KT454734 \\
\hline Leptosphaeria doliolum & CBS 541.66 & JF740206 & JF740284 & NA \\
\hline Leptosphaeria slovacica & CBS 389.80 & JF740247 & JF740315 & JF740101 \\
\hline Leptosphaeria slovacica & CBS 125975 & JF740248 & JF740316 & NA \\
\hline Neoleptosphaeria jonesii & MFLUCC 16-1442 & KY211869 & KY211870 & KY211871 \\
\hline Neoleptosphaeria rubefaciens & CBS 223.77 & JF740242 & JF740312 & NA \\
\hline Neoleptosphaeria rubefaciens & CBS 387.80 & JF740243 & JF740311 & NA \\
\hline Ophiosphaerella herpotricha & CBS 620.86 & KF498728 & DQ678062 & DQ678010 \\
\hline Paraleptosphaeria dryadis & CBS 643.86 & JF740213 & GU301828 & KC584632 \\
\hline Paraleptosphaeria nitschkei & MFLU 13-0688 & KR025860 & KR025864 & NA \\
\hline Paraleptosphaeria orobanches & CBS 101638 & JF740230 & JF740299 & NA \\
\hline Paraleptosphaeria praetermissa & CBS 114591 & JF740241 & JF740310 & NA \\
\hline Paraleptosphaeria rubi & MFLUCC 14-0211 & KT454726 & KT454718 & KT454733 \\
\hline Paraphoma radicina & CBS 111.79 & FJ427058 & EU754191 & EU754092 \\
\hline Phaeosphaeria oryzae & CBS 110110 & KF251186 & GQ387591 & GQ387530 \\
\hline Plenodomus chrysanthemi & CBS 539.63 & NR_111622 & GU238151 & GU238230 \\
\hline Plenodomus guttulatus & MFLU 151876 & KT454721 & KT454713 & KT454729 \\
\hline Plenodomus lingam & CBS 260.94 & JF740235 & JF740307 & NA \\
\hline Plenodomus salviae & MFLUCC 13-0219 & KT454725 & KT454717 & KT454732 \\
\hline Plenodomus visci & CBS 122783 & NR119957 & EU754195 & EU754096 \\
\hline Pyrenochaeta nobilis & CBS 407.76 & NR_103598 & EU754206 & DQ898287 \\
\hline Sphaerellopsis filum & CBS 234.51 & KP170655 & KP170723 & NA \\
\hline Sphaerellopsis macroconidialis & CBS 233.51 & KP170658 & KP170726 & NA \\
\hline Sphaerellopsis macroconidialis & CBS 658.78 & KP170659 & KP170727 & NA \\
\hline Sphaerellopsis paraphysata & CPC 21841 & KP170662 & KP170729 & NA \\
\hline Subplenodomus apiicola & CBS 285.72 & JF740196 & GU238040 & GU238211 \\
\hline Subplenodomus drobnjacensis & CBS 270.92 & JF740212 & JF740286 & JF740100 \\
\hline Subplenodomus valerianae & CBS 499.91 & JF740252 & JF740319 & GU238229 \\
\hline Subplenodomus valerianae & CBS 630.68 & JF740251 & GU238150 & GU238229 \\
\hline Subplenodomus violicola & CBS 306.68 & FJ427083 & GU238156 & GU238231 \\
\hline
\end{tabular}

*NA: No sequence available in GenBank.

Abbreviations: CBS: Centraalbureau voor Schimmelcultures, Utrecht, The Netherlands; CPC Collection of Pedro Crous housed at CBS; IMI International Mycological Institute, CABI-Bioscience, Egham, Bakeham Lane, U.K; MFLUCC: Mae Fah Luang University Culture Collection, Chiang Rai, Thailand. 


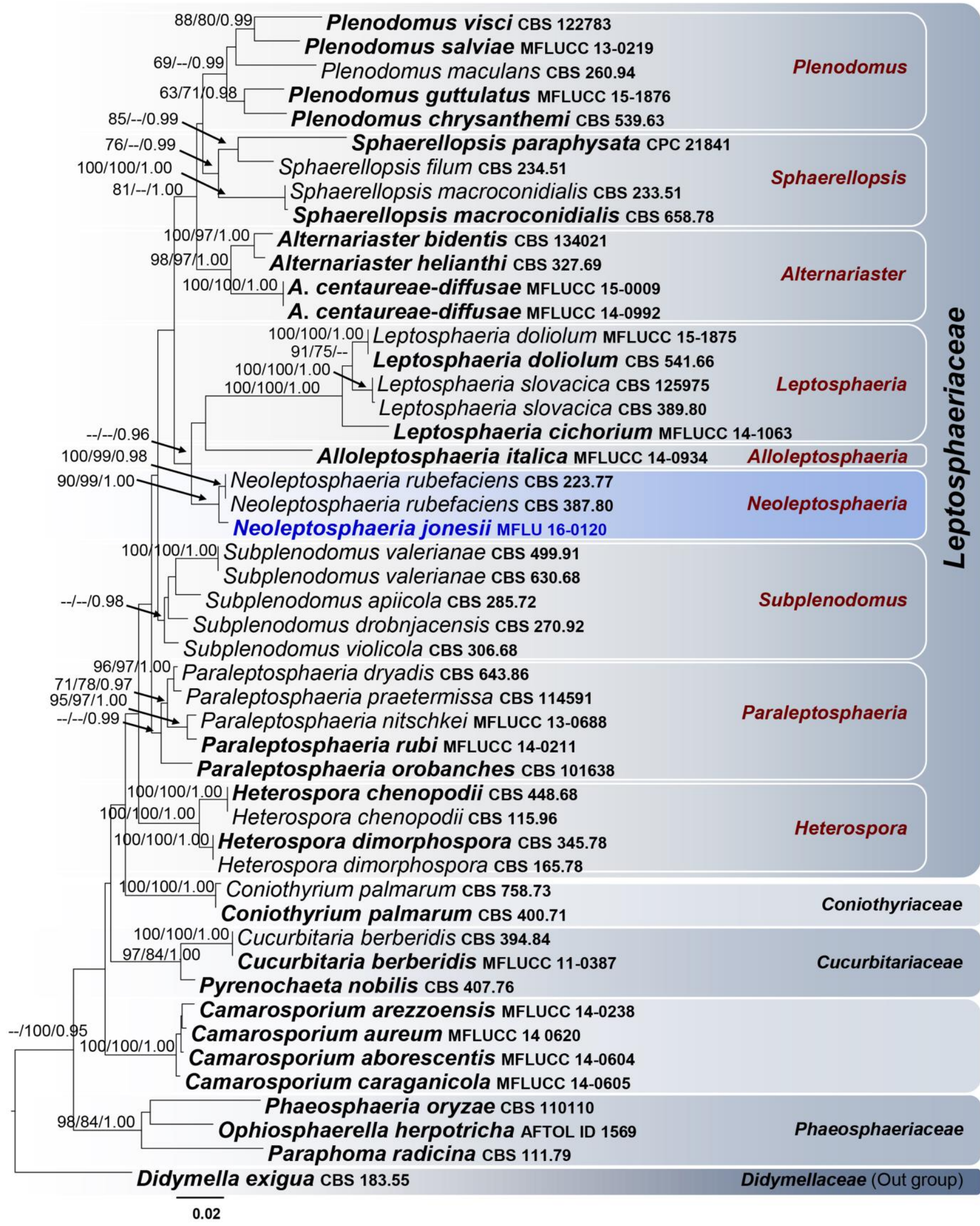

Fig. 1 - RAxML tree based on a combined dataset of LSU, SSU and ITS partial sequences. Bootstrap support values for maximum likelihood (ML), maximum parsimony (MP) higher than $70 \%$ and Bayesian posterior probabilities (BYPP) greater than 0.95 are given above the each branch respectively. The new isolate is in blue. Ex-type strains are in bold. The tree is rooted to Didymella exigua in the Didymellaceae. 
are given above each node (Fig. 1). Phylograms were visualized with FigTree v1.4.0 program (Rambaut, 2012) and reorganized in Microsoft power point (2007) and Adobe Illustrator®.

\section{Results and Discussion}

\section{Phylogenetic analysis}

The combined LSU, SSU and ITS gene dataset comprised 48 sequences with strains from Leptosphaeriaceae and our new strains. RAxML analysis yielded a best scoring tree (Fig. 1) with a final ML optimization likelihood value of -11115.225636. The matrix had 549 distinct alignment patterns, with $20.37 \%$ of undetermined characters or gaps. Estimated base frequencies were as follows; $\mathrm{A}=0.249926, \mathrm{C}=0.215820, \mathrm{G}=0.270487, \mathrm{~T}=0.263767$; substitution rates $\mathrm{AC}=1.565898, \mathrm{AG}=$ 3.058216, $\mathrm{AT}=2.269071, \mathrm{CG}=0.645547, \mathrm{CT}=7.129065, \mathrm{GT}=1.000$; proportion of invariable sites $\mathrm{I}=0.805429$; gamma distribution shape parameter $\alpha=0.572702$. The maximum parsimonious dataset consists of 2698 characters, of which 2319 were constant, 298 parsimony-informative and 81 parsimony-uninformative. The parsimony analysis of the data matrix resulted in five equally parsimonious trees with a length of 1584 steps $(\mathrm{CI}=0.399, \mathrm{RI}=0.638, \mathrm{RC}=0.255, \mathrm{HI}$ : 0.601$)$ in the first tree.

The topology of the tree is in accordance with Ariyawansa et al. (2015), Liu et al. (2015), Hyde et al. (2016) based on maximum likelihood analysis. The species in each genus are also spread throughout the tree with significant support (except Subplenodomus). Our strain of Neoleptosphaeria jonesii (MFLUCC 16-1442) grouped in an isolated clade sister to Neoleptosphaeria rubefaciens (CBS 223.77 and 367.80) with 90 \% ML, 99\% MP and 1.00 PP support (Fig. 1).

\section{Taxonomy}

Neoleptosphaeria Ariyawansa \& K.D. Hyde, Fungal Divers. 74: 36 (2015) emended. Index Fungorum Number: IF551464

Facesoffungi Number: FoF 01157

Pathogenic or saprobic on wood, bark and fruits of herbaceous or woody plants in terrestrial habitats. Sexual morph: Ascomata black, superficial to semi-immersed, fully or partly erumpent, solitary, globose, black, ostiolate. Ostiole central, short, filled with hyaline cells. Peridium composed of blackish to dark brown cells of textura angularis, cells towards the inside lighter, composed of thinwalled cells of textura angularis. Hamathecium comprising numerous, branched septate, pseudoparaphyses. Asci 8-spored, bitunicate, fissitunicate, cylindrical, short-pedicellate. Ascospores overlapping uniseriate, muriform, mostly ellipsoidal, 4-5-transversely septate, with 1 vertical septum, constricted at central septum, initially hyaline, becoming brown at maturity, slightly paler, conical and narrow at the ends, guttulate, surrounded by a mucilaginous sheath. Asexual morph: see Ariyawansa et al. (2015).

Type species - Neoleptosphaeria rubefaciens (Togliani) Ariyawansa \& K.D. Hyde, Fungal Diversity 74: 37 (2015)

Neoleptosphaeria jonesii Wanasinghe, Camporesi \& K.D. Hyde, sp. nov. Index Fungorum Number: IF552569

Facesoffungi Number: FoF 02716

Fig. 2, 3

Etymology - In honour of Prof. E.B. Gareth Jones for his immense contribution to mycology

Holotype - MFLU 16-0120

Saprobic on dead branches of Clematis vitalba L. Sexual morph: Ascomata 400-500 $\mu \mathrm{m}$ high, 420-470 $\mu \mathrm{m}$ diam. $(\overline{\mathrm{x}}=434.4 \times 462.1 \mu \mathrm{m}, \mathrm{n}=10)$, black, superficial to semi-immersed, fully or partly erumpent, solitary, globose, rough or hairy, ostiolate. Ostiole 110-150 $\mu \mathrm{m}$ long, 50-100 $\mu \mathrm{m}$ diam. $(\overline{\mathrm{x}}=$ 
$135 \times 70 \mu \mathrm{m}, \mathrm{n}=10$ ), central, smooth, with ostiolar canal filled with hyaline cells. Peridium 50-80 $\mu \mathrm{m}$ wide at the base, 30-50 $\mu \mathrm{m}$ wide at the sides, comprising 8-10 layers, with outer layer heavily pigmented, thick-walled, comprising blackish to dark brown cells of textura angularis, cells towards the inside lighter, with inner layer composed 2-3 layers, hyaline, flattened, thin-walled cells of textura angularis. Hamathecium comprising numerous, 2-3 $\mu \mathrm{m}(\mathrm{n}=40)$ wide, filamentous, branched septate, pseudoparaphyses. Asci 120-130 × 10-13 $\mu \mathrm{m}(\overline{\mathrm{x}}=124.4 \times 11.5 \mu \mathrm{m}, \mathrm{n}=40)$, 8-spored, bitunicate, fissitunicate, cylindrical, short-pedicellate, rounded at apex with a minute ocular chamber. Ascospores 19-23 × 6-8 $\mu \mathrm{m}(\overline{\mathrm{x}}=21 \times 7.5 \mu \mathrm{m}, \mathrm{n}=50)$, overlapping uniseriate, muriform, mostly ellipsoidal, 4-5transversely septate, with 1 vertical septum, constricted at middle septum, initially hyaline, becoming brown at maturity, slightly paler, conical and narrow at the ends, surrounded by a mucilaginous sheath. Asexual morph: Coelomycetous phoma-like. Pycnidia solitary to confluent, on upper surface or submerged in agar, globose to subglobose, setose, with apapillate or papillate ostiole, olivaceous to olivaceous-black, the wall with pseudoparenchymatal cells. Conidiophores hyaline, cylindrical to sub cylindrical, arising from the inner layers of conidioma. Conidiogenous cells hyaline, enteroblastic, phialidic, discrete, or integrated in septate. Conidia $3-4 \times 2-2.5 \mu \mathrm{m}(\overline{\mathrm{x}}=4.3 \times 2.3 \mu \mathrm{m}, \mathrm{n}=50)$ aseptate, cylindrical/ellipsoidal, eguttulate or with 1-2 min guttulate.

Culture characteristics - Colonies on PDA reaching $3 \mathrm{~cm}$ diam. after 30 days at $16{ }^{\circ} \mathrm{C}$, circular, smooth margin white at first, dirty white to iron after 4 weeks, flat on the surface, without aerial mycelium, reverse iron (Fig. 3). Hyphae septate branched, hyaline, thin-walled.

Known distribution - Italy, on dead twigs of Clematis vitalba.

Material examined - ITALY, Forlì-Cesena, Bagno di Romagna, Pietrapazza, on dead stem of Clematis vitalba (Ranunculaceae), 20 January 2013, Erio Camporesi, IT 1021 (MFLU 16-0120, holotype) isotype in BBH, ex-type living culture, MFLUCC 16-1442.

Notes - Neoleptosphaeria was described by Ariyawansa et al. (2015) as a monotypic genus to accommodate $N$. rubefaciens. Two strains of Neoleptosphaeria rubefaciens were included in the phylogeny of Ariyawansa et al. (2015) viz. CBS 223.77, isolated from twig of Quercus sp. (Fagaceae) in Switzerland and CBS 223.77, isolated from wood of Tilia europaea (Tiliaceae) in the Netherlands, and no sexual morph was reproted (De Gruyter et al. 2013). Here we add the asexual and sexual morphs of Neoleptosphaeria jonesii from Clematis vitalba in Italy. Neoleptosphaeria jonesii resembles N. rubefaciens in having cylindrical/ellipsoidal, hyaline conidia with 1-2 guttules. The morphology of the sexual morph of Neoleptosphaeria jonesii is more close to Leptosphaeria doliolum, Cucurbitaria berberidis and Camarosporium arezzoensis in having globose ascomata, a central ostiole filled with hyaline cells, sides of peridium wider than at the base, cylindrical, short-pedicellate asci which are rounded at apex and with a minute ocular chamber, and overlapping uniseriate, ellipsoidal, muriform ascospores which are mostly, conical and narrow at the ends (Hyde et al. 2013, Ariyawansa et al. 2015, Tibpromma et al. 2015). However they are not closely related in multi-gene analyses (Fig. 1).

Consequently, based on the morphology of asexual morph and the phylogeny we introduce our new taxon, Neoleptosphaeria jonesii as the second species of Neoleptosphaeria. In Leptosphaeriaceae, the sexual morphs of Pseudoleptosphaeria, Sphaerellopsis and Subplenodomus are still undetermined. Further collections with fresh specimens are needed to link the asexual-sexual morphs.

\section{Acknowledgments}

Dhanushka Wanasinghe extend his sincere appreciations to Prof. E.B.G. Jones for funding his research. Dian-Ming Hu thanks the grant number NSFC 31460009 and NSFC 31500021 for funding this research.

\section{References}




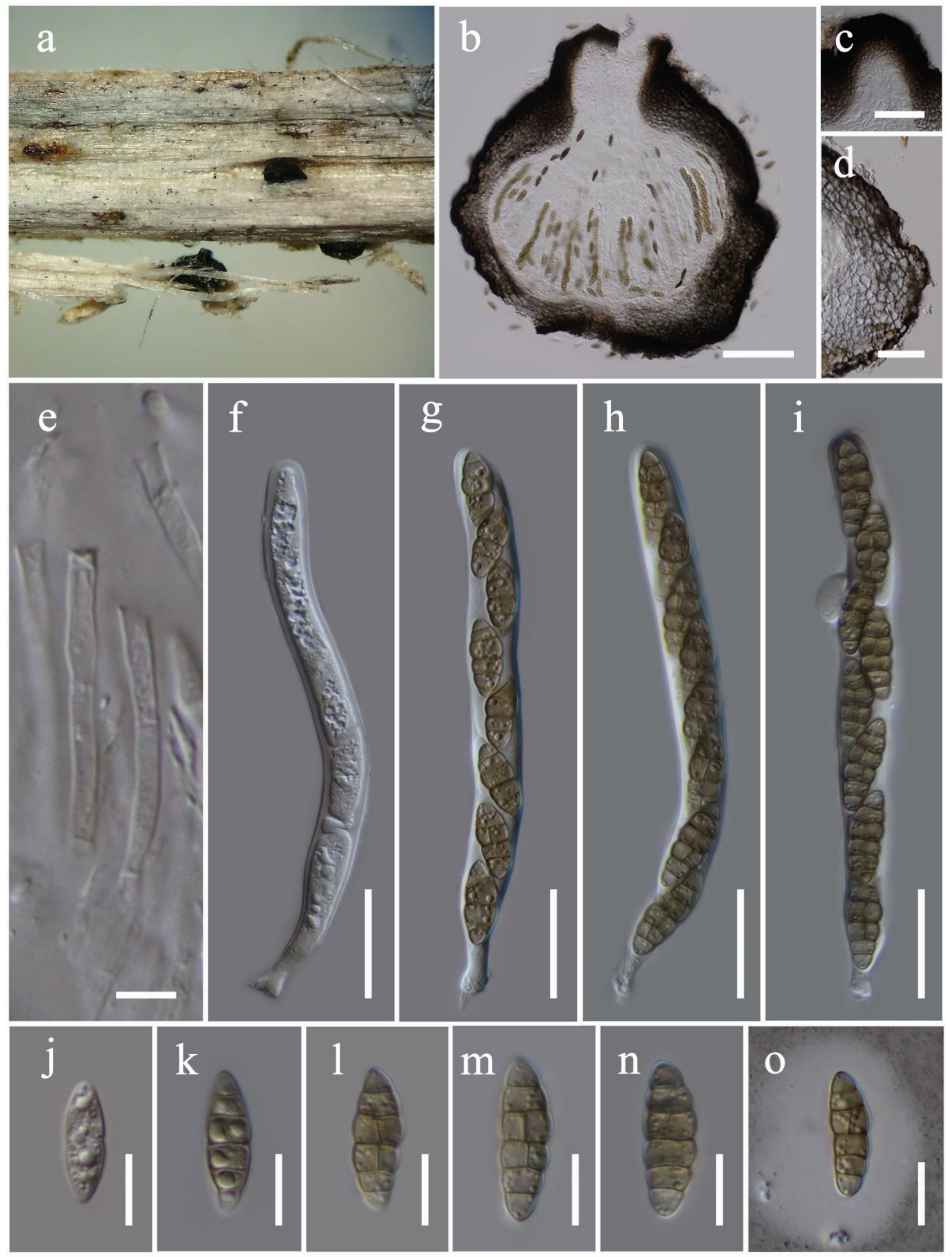

Fig. 2 - Neoleptosphaeria jonesii (holotype). a. Appearance of ascomata on host substrate. b. Section of ascoma. c. Close up of ostiole. d. Peridium. e. Pseudoparaphyses. f-i. Asci. j-o. Ascospores (note the ascospore stained in Indian ink to show the mucilaginous sheath in o). Scale bars: $b=100 \mu \mathrm{m}, c, d=50 \mu \mathrm{m}, \mathrm{e}=5 \mu \mathrm{m}, \mathrm{f}-\mathrm{i}=20 \mu \mathrm{m}, \mathrm{j}-\mathrm{o}=10 \mu \mathrm{m}$. 

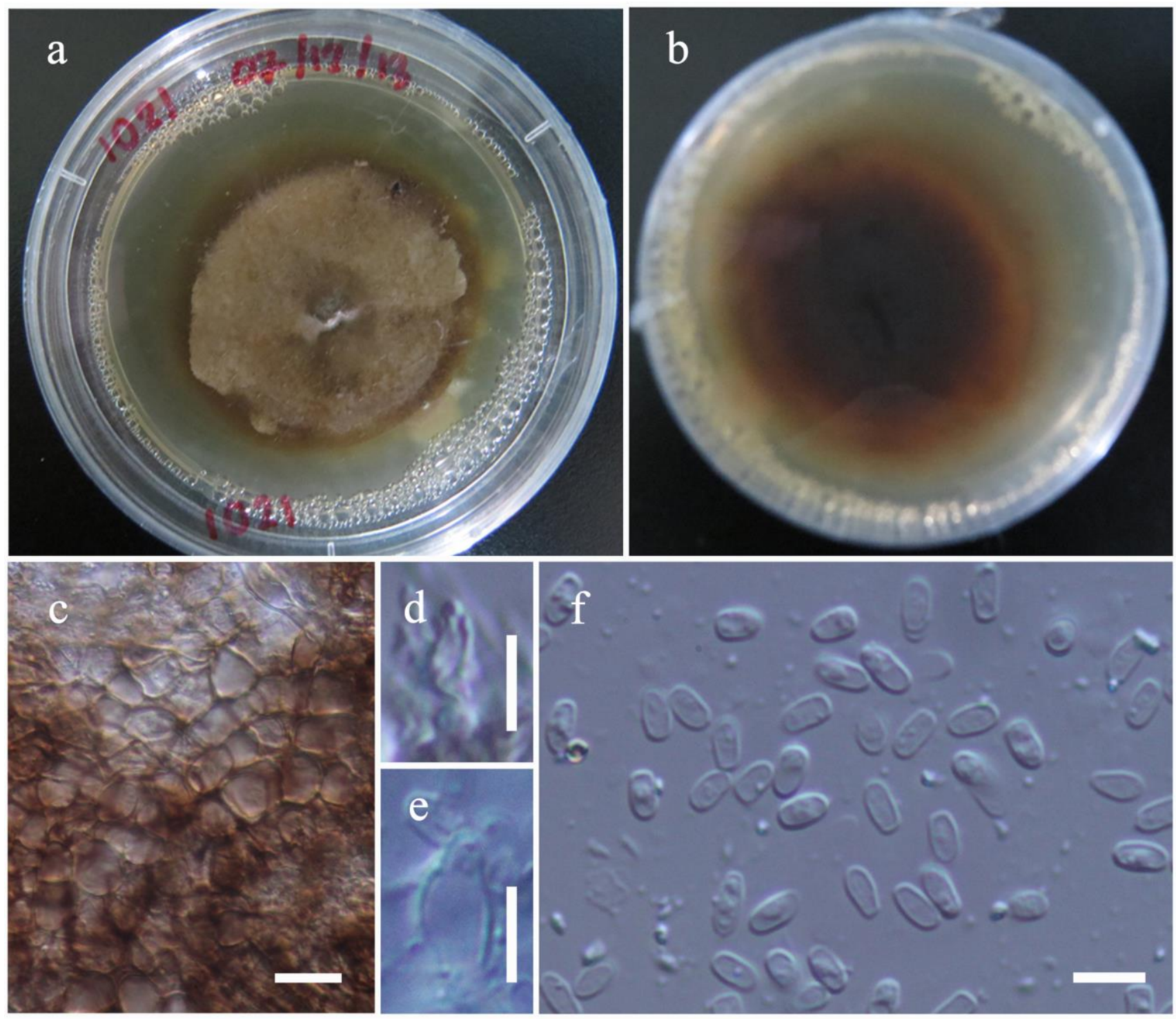

Fig. 3 - Neoleptosphaeria jonesii (ex-type culture). a,b Culture on PDA (note b reverse). c Peridium cells of squashed conidiomata. d,e Conidiogenous cells. f Mature and immature conidia. Scale bars: c $=10 \mu \mathrm{m}, \mathrm{d}-\mathrm{f}=5 \mu \mathrm{m}$.

Alves JL, Woudenberg JHC, Duarte LL, Crous PW, Barreto RW. 2013 - Reappraisal of the genus Alternariaster (Dothideomycetes). Persoonia 31, 77-85.

Ariyawansa HA, Phukhamsakda C, Thambugala KM, Bulgakov TS et al. 2015 - Revision and phylogeny of Leptosphaeriaceae. Fungal Diversity 74, 19-51.

Barr ME. 1987 - New taxa and combinations in the Loculoascomycetes. Mycotaxon 29:501-505.

Chomnunti P, Hongsanan S, Aguirre-Hudson B, Tian Q et al. 2014 - The sooty moulds. Fungal Diversity 66, 1-36.

De Gruyter JD, Woudenberg JHC, Aveskamp AA, Verkley GJM et al. 2013 - Redisposition of phomalike anamorphs in pleosporales. Studies in Mycology 75, 1-36.

Hall TA. 1999 - BioEdit: a user-friendly biological sequence alignment editor and analysis program for Windows 95/98/NT. Nucleic Acids Symposium Series 41, 95-98.

Huelsenbeck JP, Ronquist F. 2001 - MRBAYES: Bayesian inference of phylogenetic trees. Bioinformatics 17, 754-755. 
Hyde KD, Jones EBG, Liu JK, Ariyawansa H et al. 2013 - Families of Dothideomycetes. Fungal Diversity 63, 1-313.

Hyde KD, Hongsanan S, Jeewon R, Bhat DJ et al. 2016 - Fungal diversity notes 367-490: taxonomic and phylogenetic contributions to fungal taxa. Fungal Diversity 80, 1-270.

Index Fungorum. 2016 - http://www.indexfungorum.org/Names/Names.asp.

Jayasiri SC, Hyde KD, Ariyawansa HA, Bhat J et al. 2015 - The Faces of Fungi database: fungal names linked with morphology, phylogeny and human impacts. Fungal Diversity 74, 3-18.

Katoh K, Standley DM. 2013 - MAFFT multiple sequence alignment software version 7: improvements in performance and usability. Molecular Biology \& Evolution 30, 772-780.

Kishino H, Hasegawa M. 1989 - Evaluation of the maximum likelihood estimate of the evolutionary tree topologies from DNA sequence data, and the branching order in hominoidea. Journal of Molecular Evolution 29, 170-179.

Liu JK, Hyde KD, Jones EBG, Ariyawansa HA et al. 2015 - Fungal diversity notes 1-110: taxonomic and phylogenetic contributions to fungal species. Fungal Diversity 72, 1-197.

Miller MA, Pfeiffer W, Schwartz T. 2010 - Creating the CIPRES science gateway for inference of large phylogenetic trees. Proceedings of the Gateway Computing Environments Workshop (GCE), November 14, 2010, New Orleans, Louisiana 1-8.

Nylander JAA. 2004 - MrModeltest 2.0. Program distributed by the author. Evolutionary Biology Centre, Uppsala University.

Rambaut A, Drummond AJ. 2007 - Tracer v1, 4. Available from: http://beast.bio.ed.ac.uk/Tracer.

Rambaut A. (2012 - FigTree version 1.4.0. Available at http://tree.bio.ed.ac.uk/software/figtree/

Rannala B, Yang Z. 1996 - Probability distribution of molecular evolutionary trees: a new method of phylogenetic inference. Journal of Molecular Evolution 43, 304-311.

Rehner SA, Samuels GJ. 1994 - Taxonomy and phylogeny of Gliocladium analysed from nuclear large subunit ribosomal DNA sequences. Mycological Research 98, 625-634.

Stamatakis A. 2014 - RAxML version 8: a tool for phylogenetic analysis and post-analysis of large phylogenies. Bioinformatics 30, 1312-1313 http://dx.doi.org/10.1093/bioinformatics/btu033)

Stamatakis A, Hoover P, Rougemont J. 2008 - A rapid bootstrap algorithm for the RAxML web servers. Systematic Biology 57, 758-771.

Swofford DL. 2002 - PAUP: phylogenetic analysis using parsimony, version 4.0 b10. Sinauer Associates, Sunderland.

Thompson JD, Gibson TJ, Plewniak F, Jeanmougin F, Higgins DG. 1997 - The CLUSTAL_X windows interface: flexible strategies for multiple sequence alignment aided by quality analysis tools. Nucleic Acids Research 25, 4876.

Tibpromma S, Wijayawardene NN, Manamgoda DS, Boonmee S et al. 2016 - Camarosporium arezzoensis on Cytisus sp., an addition to sexual state of Camarosporium sensu stricto. Saudi Journal of Biological Sciences 23, 1-8.

Trakunyingcharoen T, Lombard L, Groenewald JZ, Cheewangkoon R et al. 2014 - Mycoparasitic species of Sphaerellopsis, and allied lichenicolous and other genera. IMA Fungus 5, 391-414.

Vilgalys R, Hester M. 1990 - Rapid genetic identification and mapping of enzymatically amplified ribosomal DNA from several Cryptococcus species. Journal of Bacteriology 172, 4238-4246.

White TJ, Bruns T, Lee S, Taylor J. 1990 - Amplification and direct sequencing of fungal ribosomal RNA genes for phylogenetics. In: Innis MA, Gelfand DH, Sninsky JJ, White TJ (eds) PCR protocols: a guide to methods and applications. Academic Press, San Diego, pp. 315-322.

Zhaxybayeva O, Gogarten JP. 2002 - Bootstrap, Bayesian probability and maximum likelihood mapping: exploring new tools for comparative genome analyses. BMC Genomics 3, 4. 